\title{
Gender and Climate Change: Giving the "Latecomer" a Head Start
}

\author{
Fatma Denton
}

\section{Introduction}

Gender mainstreaming is now considered as an integral part of development, both in terms of conceptualisation and practice. Nonetheless, the planning practice necessary to effect wide-scale change has not always been concordant with the larger body of conceptual knowledge (Moser 1991: 83). Similarly, linking gender to climate change did not always seem obvious to many development researchers and practitioners. Yet, there is sufficient evidence to substantiate the theory that climate change has numerous development and environmental implications which will impact negatively on women and men, but in a differentiated manner.

As discussed by Kjellén in this Bulletin, getting states to conjugate environment and development in one sentence was a huge challenge, especially for developing countries whose electoral mandate tends to be heavily premised on development priorities such as access to clean water, healthcare, education for all and better employment opportunities. The 1972 Stockholm Conference laid down the foundation for bringing development and environment under a single banner; but for many developing countries this twinning remained academic until the Rio Conference in 1992. Since then, scientists and policy makers have focused their attention on integrating environment and development. Like the other Rio Conventions, the 1992 United Nations Framework Convention on Climate Change (UNFCCC) is an agreement that encapsulates that focus. Although gender issues are now an integral part of development, they remain far removed from the cut and thrust of mainstream climate policy.

This article first seeks to illustrate the different strands of the gender and climate debate and offers possible suggestions of why gender was almost perceived as an afterthought in the climate discussions. Second, it looks at three climate sensitive areas: agriculture, water and energy, and how adaptation strategies could be crafted to help women and men in these sectors. Third, the article looks at the general discourse on gender and development and identifies lessons that could be learnt by gender and climate change activists.

\section{Main trends on the gender and climate change literature}

Gender issues made a slow entry into the climate debate. This was partly due to the varied competing priorities and to some extent the fact that climate change was perceived as a global phenomenon, with little attention being paid to differentiating the potential impacts that women and men might face. The bulk of the literature concentrated on discussion of impacts at aggregate levels, principally at global level because early climate models could only give information about global and in some cases, at the regional impacts. Subsequent socio-economic studies of the impacts of climate change then tended to overlook or mask the unequal risks arising from climate change potentially facing different kinds of groups within a country, including masking the differences in impacts as between men and women (Masika 2002). ${ }^{1}$ Early studies focused on the human security aspects drawing on the need for social justice in the environment and emphasising the fact that environmental governance is layered with gender implications (Denton 2000). Women have the key responsibility of fetching water, fodder, collecting firewood, all very much part of the rural landscape and the mindsets of many societies where such activities rest squarely on women's shoulders and those of their children. Consequently, they bear 
almost disproportionate hardships relating to both the provision and shortages of such vital necessities. More recently, a large part of the gender/climate debate has been dedicated to demonstrating the significance of disaggregating policy implications of mitigation and adaptation options, thereby highlighting the relevance of gender issues to climate change, including an issue such as capacity development (Wamukonya and Skustch 2001).

\section{Why was gender the latecomer in the climate change debate?}

As mentioned above, gender issues made a late entry into the climate research and policy debates. The reasons for this are numerous. The following could be noted as possible explanations.

\subsection{North/South cleavage}

Initial discussions on climate change were soon reduced to North/South divisions (Gupta 1999: 200). Developing countries remained convinced that the North had an undeniable moral imperative to "clean up its act" due to its lavish consumptive patterns. In the absence of carbon-free alternatives, developing countries demanded the right to increased emissions to meet their future social, economic and developmental needs, framing such emissions largely as "survival emissions", as these were perceived by them to be necessary to convert their own struggling economies into flourishing ones capable of meeting their citizens' current and future needs (Mwandosya 1999). Developed nations were, on the other hand, equally eager to see the South taking a more proactive stance to curb environmental degradation. The focus on North/South dynamics has tended to overshadow the fact that it is the poor, within both developed and developing countries, who will bear the sharpest burdens due to the adverse effects of climate change. Because women tend to make up a greater proportion of the poor, aggregation at the North/South level has masked the higher risks that poor communities within developing countries, particularly the women within such communities, face from climate change.

\subsection{Market-driven ethos}

The climate regime, like other development discourses in the 1990s, was driven by market considerations and the belief that once established, carbon markets will function to benefit all, while also achieving Kyoto's environmental ends (Denton 2002: 11-20). The idea that global carbon markets would be the panacea to climate mitigation certainly held sway in the run up to Kyoto and immediately thereafter. Flexible financial mechanisms such as the Clean Development Mechanism (CDM) together with International Emission Trading (IET) and Joint Implementation (JI) were created. These acronyms soon became the buzz words of the day as companies as well as states were convinced by promarket hyperbole that such market-based mechanisms would lead to huge potential business opportunities that would translate into financially valuable credits which, if freely traded, would result in economic gains for all. Gender matters are often perceived as social justice issues with huge implications for poverty alleviation. Because neither poverty nor social justice featured large in climate vocabulary, gender, by association, was left to simmer on the back burner, along with poverty alleviation and broader human security and social issues, which are only now being seriously integrated into economic and environmental issues (see Kjellén, this Bulletin).

\subsection{Strong focus on physical aspects of climate change}

Another reason why the climate regime neglected gender issues is because the dominant issues in the early part of the regime were concerned with the causes of climate change-issues that were heavily dependent on answers from the natural, rather than the social, sciences. The general climate literature deals most effectively with the physical causes and impacts of climate change, such as changes in precipitation, rising sea levels and impacts on river deltas, low-lying coastal areas and arid and semi arid zones, and on phenomena such as the disappearance of Lake Chad. Although the Intergovernmental Panel on Climate Change (IPCC) has always examined the socio-economic literature on climate mitigation and adaptation, its assessments have been hampered by the fact that very little literature on gender and other developmental linkages existed in the first decade as well as by the fact that the majority of IPCC lead authors were men from developed countries, usually with strong academic, rather than development policy, backgrounds. The lack of development orientated researchers as lead authors due in part to the difficulty of finding candidates from 
developing countries (male and female), to take part in IPCC processes because of human, institutional and capacity constraints, meant the lack of a gender focus was not much commented upon in the IPCC's first and second assessment reports. It should be emphasised here that climate change is not an exception in this regard. Agenda 21 attributes a central role to women in the area of environmental sustainability and governance (Global Environment Outlook 3 2002: 16). ${ }^{2}$ Yet, neither this authoritative document nor other successive ones have played any great role in addressing the gender myopia that is still largely prevalent in the environment and climate change world.

\section{Making gender sense of three climate sensitive sectors: agriculture, water and energy - the Sahelian experience}

There are encouraging signs however, that gender issues are beginning to be taken into consideration in climate policy. As far as representation is concerned, at COP 7 held in Marrakesh, 2001, the Conference of the Parties (COP) agreed on a decision that emphasised the importance of trying to attain gender balance when Parties nominate members for elected posts (Decision 36/7). In policy terms, the decisions adopted by the same COP relating to adaptation planning by least developing countries (LDCs) require, for the first time in climate decisions, that due consideration be given to gender equality (Decision 28/7). These references indicate growing sensitivity among climate policy makers of the need to give greater explicit consideration in policy and process terms to gender issues. To further this sensitivity, this section highlights the gender dimensions of how three sectors that are particularly critical for developing countries and poorer communities will be impacted. These sectors are agriculture, water and energy - all of which are likely to be prominent on the climate impacts casualty list.

\subsection{Agricultural sector}

Much of Africa is dependent on agriculture for its export earnings. Agricultural productivity in the Sahel has been hit considerably by external factors such as declining terms and perverse subsidies in richer advanced economies, and price structures weighted against developing countries. These are exacerbated by internal factors such as low productivity, environmental degradation, land use change, poor agricultural policies and structuralrelated constraints (Global Environment Outlook 32002: 70-5). The monocrop pattern of agriculture practised in most developing countries - a colonial legacy - has accentuated the dependency of farmers and left them extremely vulnerable. The rural poor, both women and men, are faced with myriad constraints such as diminishing water resources and poor soil quality due to leaching and nutrient deficit. In a recent study conducted in Senegal by Enda Energy, findings revealed growing food insecurity in all 13 villages being studied. ${ }^{3}$ Food security is also a severe problem in the Sahel due to low agricultural yield, desertification and to the nature of an agricultural system largely dependent on rainfall. As Khadija B. attests:

We are poor because we do not have rainfall; the little we have is not enough to feed us. During the month of August we tend to eat what we have harvested. (Khadija B.-Ibel, Female) ${ }^{4}$

In many parts of the Sahel, women are responsible for the bulk of agricultural production, including subsistence farming. Some 80 per cent of women are actively engaged in agricultural activities in sub-Saharan Africa (World Development Report 2003: 71).

Rice production in wetland fields is an important resource for food production, but its production could be adversely by climate change. Women are actively involved in the production of rice in Africa, Asia and Latin America. Rice is not just an important staple commodity in many developing countries, it also provides 8 per cent of the food energy for almost 1 billion people (Neue 2004). With increased pressure for rice production, women, who provide the bulk of the labour in this area, may have to contend with dwindling resources and climatic stresses that could impact negatively on productivity. Women and men would need to be introduced to suitable adaptation and mitigation strategies that would promote rice production and lower methane emissions (methane from rice production is a significant cause of climate change in many developing countries).

The sustainability of wetland production and its effects on soils would call for a diversification of agricultural systems and a transition towards the 
production of vegetables, plantation crops, the rearing of livestock and other remunerating activities. Addressing water management issues is also very pertinent to a sustainable rice production and women must be made aware of the varied options and potential benefits of such strategies. Women's active involvement in rice production must be factored into adaptation strategies such as training and institutional support, better credit facilities and in-depth knowledge of crop species and crop marketing. Increased availability in food benefits the whole community. However, food insecurity places more burden on women who often have to expend several hours on labour intensive work to make up for such shortages, not to mention taking nutritional shortcuts to cater for the family. The Global Environment Facility (GEF), the institution in charge of the Convention's financial mechanism, could use its small grants programme to initiate more projects that would satisfy food security needs, such as through the provision of clean, reliable and affordable energy services for community development. ${ }^{5}$ Communities are already adapting to environmental degradation as part of their coping and survival strategies. However, crafting adaptation strategies would mean addressing many of the above structural constraints. Adaptation funds will help Least Developed Countries (LDCs) kick start activities under the National Adaptation Programme of Actions (NAPAs), but they will need greater support from donors and other actors if they are to succeed (see Huq and Reid, this Bulletin).

\subsection{Water sector}

Water is one of the defining and most pressing needs of the twenty-first century. More than 1 billion people in low- and middle-income countries and 50 million people in high-income countries lack access to safe water supplies (World Development Report 2003: 2). Water-related conflicts are beginning to occur, especially with shared water basins such as the Nile and the Kovango (Magadza 2003: 262-3). There is already a great deal of competition for water supplies - all of this will become more acute with climate change and extreme events (see Burton and May, this Bulletin). Reduced flow in water will ultimately affect areas that are already water-stressed and women and men facing such severe shortages will have to rely on their organisational strategies and local management to cope with the severity of water as a result of extreme events or climate-related incidents.

In the developing world, water scarcity is a major problem and women invariably have to take responsibility for its collection, but also to ensure that the water is adequately treated to avoid water contamination. Time poverty and demanding household chores often mean that women are unable to treat water for their family and children are often extremely vulnerable to poor water quality.

The children are fed up too and there are far too many risks associated with drinking dirty water. What is worse is that they arrive home with a cold and they start to cough and although we have other competing priorities we have no choice but to take them to the health centre. It starts with a cold and ends with something more complicated. Very often we cannot tell which well is the culprit. (Diara Tine-Gadiag, Female) ${ }^{6}$

Scarcity of fresh water supplies would also increase vector-borne diseases such as malaria and the frequency of illnesses such as diarrhoea. Intense rainfall would cause more floods and accentuate existing environmental hazards. Water has huge human security implications and crosscuts all human activities. Already 1.7 billion people are living in water stressed areas (UNEP and UNFCC 2001). Flood run-off would also reduce the amount of surface water and hence diminish the livelihood potential for women and men who depend on irrigation-fed agriculture. Poor water infrastructure increases the pressure on women to seek other options and resort to paying for water often at the detriment of other nutritional needs. Adaptation strategies must also seek to address existing structural problems as well as develop coping strategies that would make effective use of available water, taking gender implications into account. Improved water resource management would reduce vulnerability and help towards conservation methods, while reducing water pollution. Reviewing the gender division of labour in terms of who does what, may help development practitioners craft the right adaptation strategies according to the differential needs of women and men.

\subsection{Energy sector}

In global terms, after emissions from the burning of fossil fuels, deforestation is the second largest 
source of carbon dioxide and for many developing countries represents a large part of their greenhouse gas (GHG) emissions. Constant land clearing for agricultural use and the cutting down of trees can have devastating consequences on environmental resources. In Africa, desertification has prompted Sahelian governments to embark on energy efficiency and diversification projects with the introduction of Liquefied Petroleum Gas (LPG) in Senegal in 1974 (Sokona and Dème 2000). Increased access to energy services in the developing world is a major development challenge. Energy poverty is often characterised by wealth and status, with the majority of the poorer nations having nothing else to contend with but wood, twigs, charcoal, cow dung and their own human energy to name but a few energy resources. Wood consumption constitutes 92 per cent of total wood consumption in Africa. Limited access to energy services places women in an unenviable situation - constantly in the quest of firewood and liable to pay fines imposed by forest agents for breaching the law.

We do not have access to firewood because there is a formal ban on this by the forestry agents and we are liable to pay fines if we are caught in the act. (Astou Dione - Ndondol, Female) ${ }^{7}$

Energy efficient projects of the Clean Development Mechanism (CDM) have been initiated in different corners of the developing world with varying degree of success (GEF/UNDP/UNOPS 2003: 3-16). However, a lot more needs to be done to help women make the transition from using inefficient and labour-intensive instruments such as the pestle and mortar, to more efficient and timesaving devices. It is an irony that while a number of developing countries have focused the bulk of their energy policies on energy efficiency with the promotion of improved stoves, only a few communities have been able to benefit from such cooking devices. Moreover, this policy has reduced energy poverty down to the sole problem of cooking. Access to affordable energy services is not just an intrinsic right, it is fundamental to poverty alleviation and the achievement of the genderrelated Millennium Development Goals. As Bintou poignantly asks: 'How can I speak of development if I have to go into the bush every day to collect wood?'8
There is a need to look at diversifying options to include waste management projects that would improve agricultural productivity and waste options that can be converted to energy. CDM and GEF projects could help women take advantage of appropriate energy technologies and decentralised energy systems that would open new market opportunities, reduce poverty and air pollution, improve the quality of life of women and men and offer integrated services in key sectors such as water, energy, education and heath. Equally, introducing forest management projects that take into account women's indigenous knowledge and offer new skills to help improve crop species, soil quality and water conservation could also prove to be very beneficial to rural communities (see Leach and Leach, this Bulletin). Local community projects could also be a purveyor of funds for women wishing to embark on specific activities such as sustainable harvesting of forestry products (Skustch 2002: 37). Women are also in dire need of energy services that would add value to their agricultural products and preserve vegetables, as well as process their cereals and other staple commodities.

\section{Lessons from gender/ development discourses}

As the foregoing section demonstrates, implementation of climate mitigation and adaptation policies needs to be more gender sensitive if such policies are to achieve their stated aims. But at the same time, the climate regime can learn from the history of incorporation of gender issues in other development discourses.

\subsection{Ghettoisation}

The general discourse on gender has come a long way from the days of Women in Development (WID) - addressing diverse issues from welfare to empowerment and citizenship (see Gender and Development In Brief, IDS 2004). The climate change regime should seek to integrate women's concerns but without making it a special basket case and insulating such issues from the wider discourses about the overall environmental constraints faced by everyone. Goetz, for example, argues that 'separate women's projects have provided planners with alibis to prove their commitment to basic needs without having to deal with the implications of treating women as equal agents in development' (Goetz 1991). 


\subsection{Concept of sameness}

Presenting women's problems as a single agenda also runs the risks of conflating the issue and thus putting all third world women under the banner of poverty, patriarchy and male subordination. Differences may abound in the same country, depending on geographical context, in the same way that similarities are present. One of the strengths of feminist theory was to open up issues previously aggregated under groupings that masked gender and power imbalances. Greater attention to gender analysis in climate change should supplement, not supplant, other dimensions, such as class, ethnicity and regional affiliations, which also determine the climate-related implications for men and women.

\subsection{Representational voices versus "goodwill" ambassadors}

The opportunity for women to participate effectively in national and international policy-making processes so that their voices are heard, still remains limited and often skewed in favour of men. Often, the role of representation is appropriated by elite women whose realities are often far removed from the so-called "victims" they claim to represent. Very often, subjectivity, belief systems and notions of equality, empowerment and justice are brought into the debate, which may mean that the policy prescriptions espoused by the elite bring few benefits to the group as whole. Rural women also want and aspire to such values but culture and societal restrictions may prevent them from participating effectively in formal processes.

\subsection{Obsessive conceptualisation and little appreciation of the field and its diversity}

Linking climate change to development must mean that participation from communities must be actively sought. There are many examples of imposing project ideas on communities. Project ideas, however ingenious, tend to lack ownership, especially when they are foisted on rural communities who are asked to validate such projects at the later stages of project implementation. Climate change and gender-related implications could be discussed with communities prior to policy prescriptions being imposed. The knowledge and experience of communities in devising coping strategies must not only be sought, but encouraged and respected, as these are likely to be well suited to the practical experience of such communities and commensurate with their current coping skills. Equally, field experiences drawn upon by communities will be worthless if they do not provide pathways for the future.

\subsection{Culture of pitting women against men}

Sustainable development is about building a partnership between women and men. The current culture of pitting women against men may be a disincentive to encouraging change, compromise and negotiation between the two groups. Gender relations are invariably characterised by power relations, but such relations do not negate opportunities for complementarity and partnerships. Changing deeply entrenched societal modes of behaviour does not happen overnight. Women in rural communities are often keen to seek harmony within their households irrespective of their daily trajectories, in order to achieve such goals. Men are often perceived as victims of an incapacitated system consumed by the many faces of poverty, greed and deprivation.

\subsection{Exploiting synergies and development partnerships}

Exploiting synergies should go beyond forging close ties with immediate beneficiaries. There is an obvious polarisation between the development and climate change world, in spite of the many opportunities for synergies. This polarisation also extends to the scientists and development practitioners in times when unity could mean an enriched literature both in terms of enhanced knowledge and practical solutions for reducing the harmful effects of climate change. Artificial divisions may hence prove to be disastrous, especially since environment and development are two faces of the same coin. It is therefore important to establish collaborative research groups that cut across political (e.g. North/South) and disciplinary boundaries and do so in an integrated fashion by linking the relevant Convention on desertification, biodiversity and climate change, together with gender issues.

\subsection{More informed research}

The research on the linkages between climate change and gender remains in its infancy. Much of it is far too general and a lot of it is still not adequately tied to the international negotiations. Policy makers will need to know in more detail, for 
example, areas where gender mainstreaming is relevant and where it is a policy priority. National and international research bodies should seek to fund such research and to promote its dissemination to raise awareness.

\section{Conclusions}

Climate change is complex and its implications cannot be known with certainty. Many dimensions such as gender implications, remain relatively under researched. For example, existing research on male mobility and male migration patterns suggests that in times of exigency and stress, such as those that might be brought on or exaggerated by the negative impacts of climate change, women and girls are left behind to cope. The resulting increased domestic and work burdens make it difficult for them to continue their existing income-generating activities, let alone take up additional opportunities. Linking gender and climate change should go beyond demonstrating the vulnerability of women and their need for focused and tailor-made capacity development. A lot of changes would need an

\section{Notes}

1. The entirety of this journal is dedicated to gender and climate issues. In the main, it underscores the fact that gender issues have been side-tracked in the main climate policy debate. It serves as an important piece of advocacy and stresses the need to build adaptive capacity, reduce vulnerability and put in place implementable policies that would bear equitable outcome for women and men.

2. Agenda 21 gives women and other major groups, i.e. indigenous people and youth, a key role in environmental sustainability and addressing social issues.

3. The study is financed by the United Nations Development Programme under the tutelage of Enda Tiers-Monde Energy Programme. The study was conducted in Senegal in 13 villages representing a fair geographical balance, between April and August 2003. A lot of emphasis was

\section{References}

Denton, F., 2002, 'Climate change vulnerability, impacts and adaptation: why does gender matter?', in R. Masika (ed.), Gender, Development and Climate Change, Oxfam Focus on Gender, Oxford: Oxfam Publications

Denton, F., 2000, 'Gendered impacts of climate change - a human security dimension', Energia News, Vol 3 No 3, October

GEF/UNDP/UNOPS, 2003, Community Action to Address Climate Change: Case Studies Linking allocation of resources and strong political will among decision makers to appreciate gender inequities in sufficient detail to begin to incorporate such consideration in designing policy interventions. Efforts should be devoted to include a wide range of stakeholders, particularly women and the poor, whose participation in national and international policy processes is relatively recent and remains to be fully effective.

Climate change is a global phenomenon, but its consequences will impact differently on women and men. Women tend to have less access to valuable resources to help them develop their adaptive capacity to potential threats and to avoid or minimise the negative impacts of climate change. Limited access to land and land tenure and poor credit facilities could forestall poverty and hinder adaptive measures. Taking pre-emptive steps to understand and to reduce such differential impacts could help women and therefore poor communities to better adapt and avoid them being left voiceless, trapped in perennial cycles of poverty, privation and ignorance.

given to poverty and development issues based on community perceptions and real life stories of grappling with energy poverty, poor access to water, marginalisation and food insecurity. The findings will be published in the course of 2004

4. Personal Interview, Ibel, Senegal, June 2003.

5. See a portfolio of such projects in Responding to Climate Change, Generating Community Benefits, November 2003: 45-55.

6. Group interview, Gadiag, Senegal July 2003: findings of 'real life stories of energy poverty and marginalisation', joint publication Enda Tiers Monde/UNDP, July 2004.

7. Personal interview, Ndondol, Senegal, July 2003.

8. Personal Interview, Sourouyel, Senegal, June 2003.

Sustainable Energy Use with Improved Livelihoods, New York: GEF/UNDP/UNOPS, November: 3-16

Global Environment Outlook 3, 2002, Past, Present and Future Perspective, London: Earthscan Publications Ltd

Goetz, A.M., 1991, 'Feminism and the Claim to Know: Contradictions in Feminist Approaches to Women in Development', in R. Grant and K. Newland (eds), 1991, Gender and International Relations, Milton Keynes: Open University Press 
Gupta, J., 1999, 'North-South aspects of the climate change issue: towards a constructive negotiating package for developing countries', RECIEL, Vol 8 No 2: 200

Magadza, C.H.D., 2003, 'Engaging Africa in Adaptation to Climate Change', in J. Smith, R. Klein and S. Huq (eds), Climate Change, Adaptive Capacity and Development, London: Imperial College Press

Masika, R. (ed.), 2002, Gender, Development and Climate Change-Oxfam Focus on Gender, Oxford: Oxfam Publications

Moser, C.O.N., 1991, 'Gender Planning in the Third World: Meeting Practical and Strategic Needs', in R.Grant and K. Newland (eds), Gender and International Relations, Milton Keynes, Open University Press

Mwandosya, M.J., 1999, 2000 Survival Emissions: A Perspective From the South on Global Climate Change Negotiations, Crest 2000; Dar-es-Salam, 1999

Neue, H.-U., Methane Emission from Rice Fields: Wetland Rice Fields May Make a Major Contribution to Global Warming, www.ciesin.org/docs/004032/004-032.html\#rice (accessed April 2004)
Skustch, M., 2002, 'Protocol, Treaties and Action: The "Climate Change Process" Viewed Through Gender Spectacles', in R. Masika (ed.), Gender, Development and Climate Change, Oxfam Focus on Gender, Oxford: Oxfam Publications

Sokona, Y. and Dème, P.A., 2000, LPG Introduction in Senegal, communication of 'The First Meeting of the Forum on Sustainable Energy. Rural Energy: Priority for Action', 11-13 December, IIASA Headquarters, Laxenburg, Austria, accessed April 2004

UNEP and UNFCCC, 2001, Climate Change Information Kit, France: UNEP and UNFCCC

Wamukonya, N. and Skustch, M., 2001, 'COP 6: the gender issue forgotten?', Energia News, Vol 4 No 1, March

World Development Report, 2003, 'Sustainable Development in a Dynamic World: Transforming Institutions, Growth and Quality of Life', Washington, D.C.: World Bank and Oxford University Press 